\title{
Real time Monitoring of Containerless Microreactions in Acoustically Levitated Droplets via Ambient Ionization Mass Spectrometry
}

\author{
Elizabeth A. Crawford, ${ }^{\dagger}$ Cemal Esen, ${ }^{\ddagger}$ and Dietrich A. Volmer* ${ }^{\dagger}$ \\ 'Institute of Bioanalytical Chemistry, Saarland University, 66123 Saarbrücken, Germany \\ "Department of Mechanical Engineering, Ruhr-University Bochum, 44801 Bochum, Germany
}

\section{*Corresponding Author:}

Prof. Dr. Dietrich A. Volmer

Institute of Bioanalytical Chemistry

Saarland University

Campus B2.2

66123 Saarbrücken, Germany

Email: dietrich.volmer@mx.uni-saarland.de

Tel: +496813023433

Fax: +49 6813022943

\section{Table of Content:}

Figure S-1. In vitro degradation of erythromycin A at $0.01 \%$ formic acid................... S-2

Figure S-2. Data-dependent MS/MS analysis after $120 \mathrm{~s}$ in stillo reaction.................. S-3

Figure S-3. DART-MS spectra for a $60 \mathrm{~s}$ in stillo reaction across the full desorption time....S-4 Figure S-4. Results of the erythromycin A degradation reaction for in vitro experiments.... S-5

Figure S-5. Droplet evaporation of $6 \mu \mathrm{L}$ droplets across in stillo reaction times....................S-6

Figure S-6. Calculated $\mathrm{pH}$ changes as a result of droplet evaporation........................ S-7 


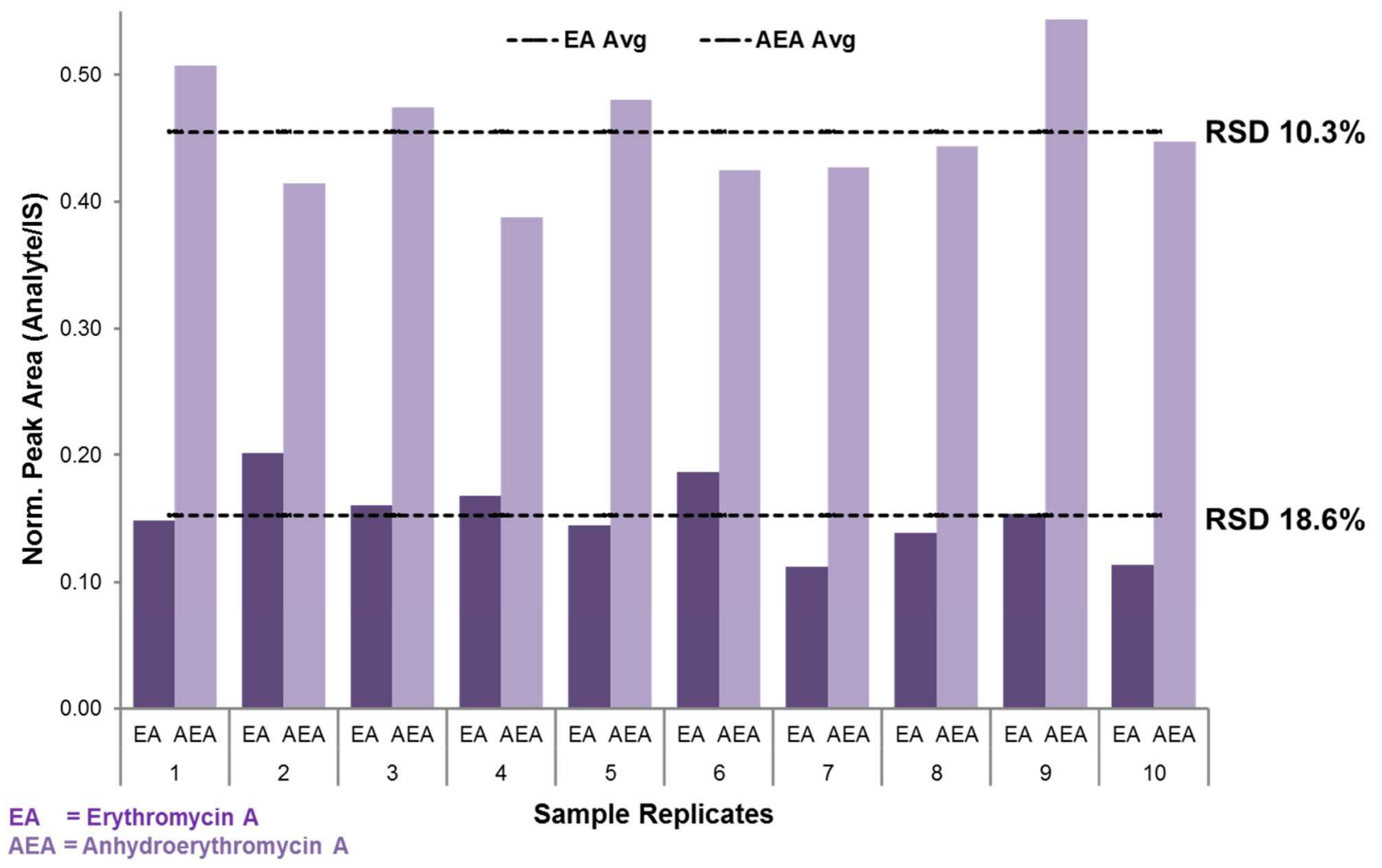

Figure S-1. In vitro degradation of erythromycin A at $0.01 \%$ formic acid. Repeatability data for ten in vitro sample replicates with $6 \mu \mathrm{L}$ analyzed droplet volumes. 


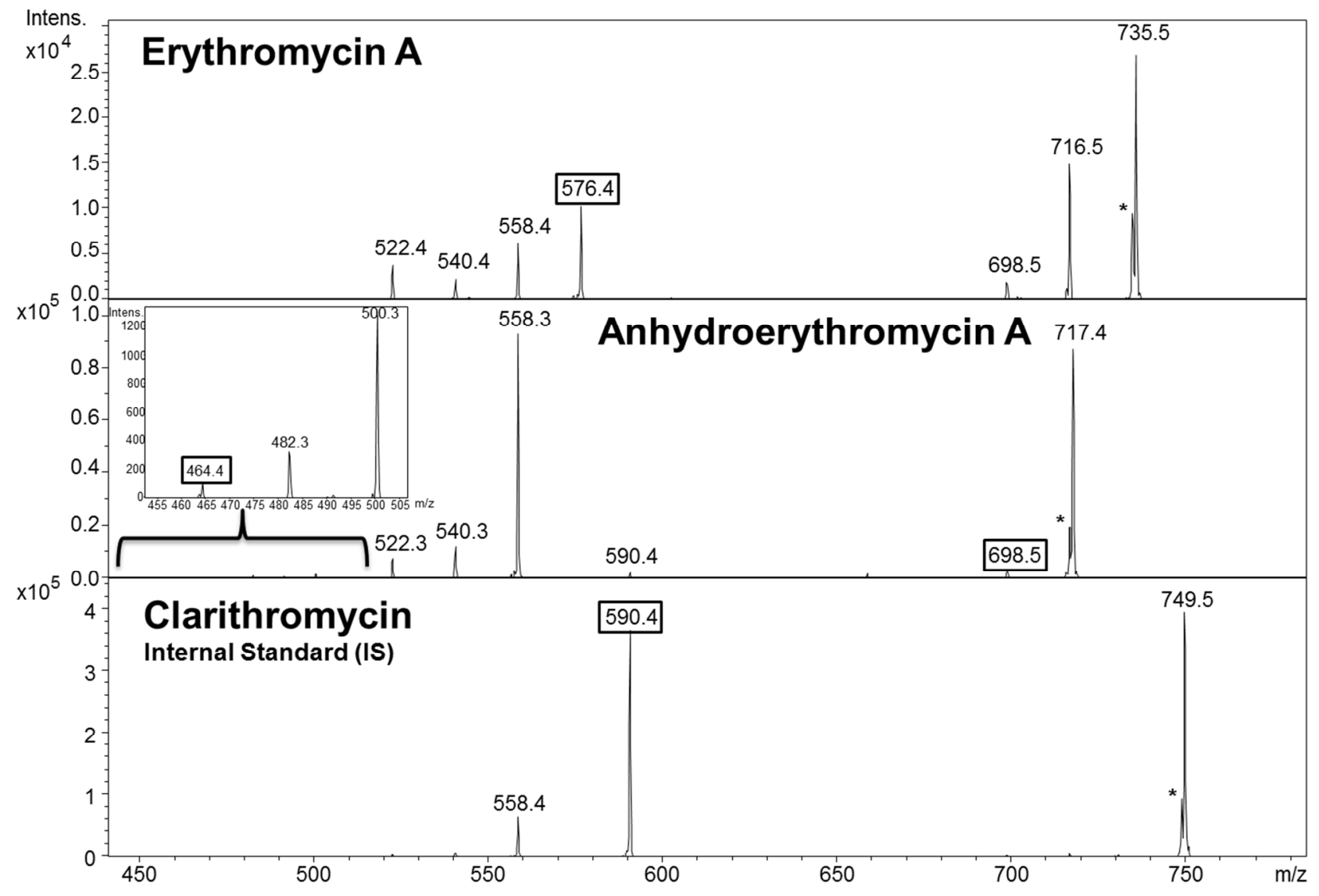

Figure S-2. Data-dependent MS/MS analysis after $120 \mathrm{~s}$ in stillo reaction. Confirmatory ions in each MS/MS spectral fingerprint are circled. 


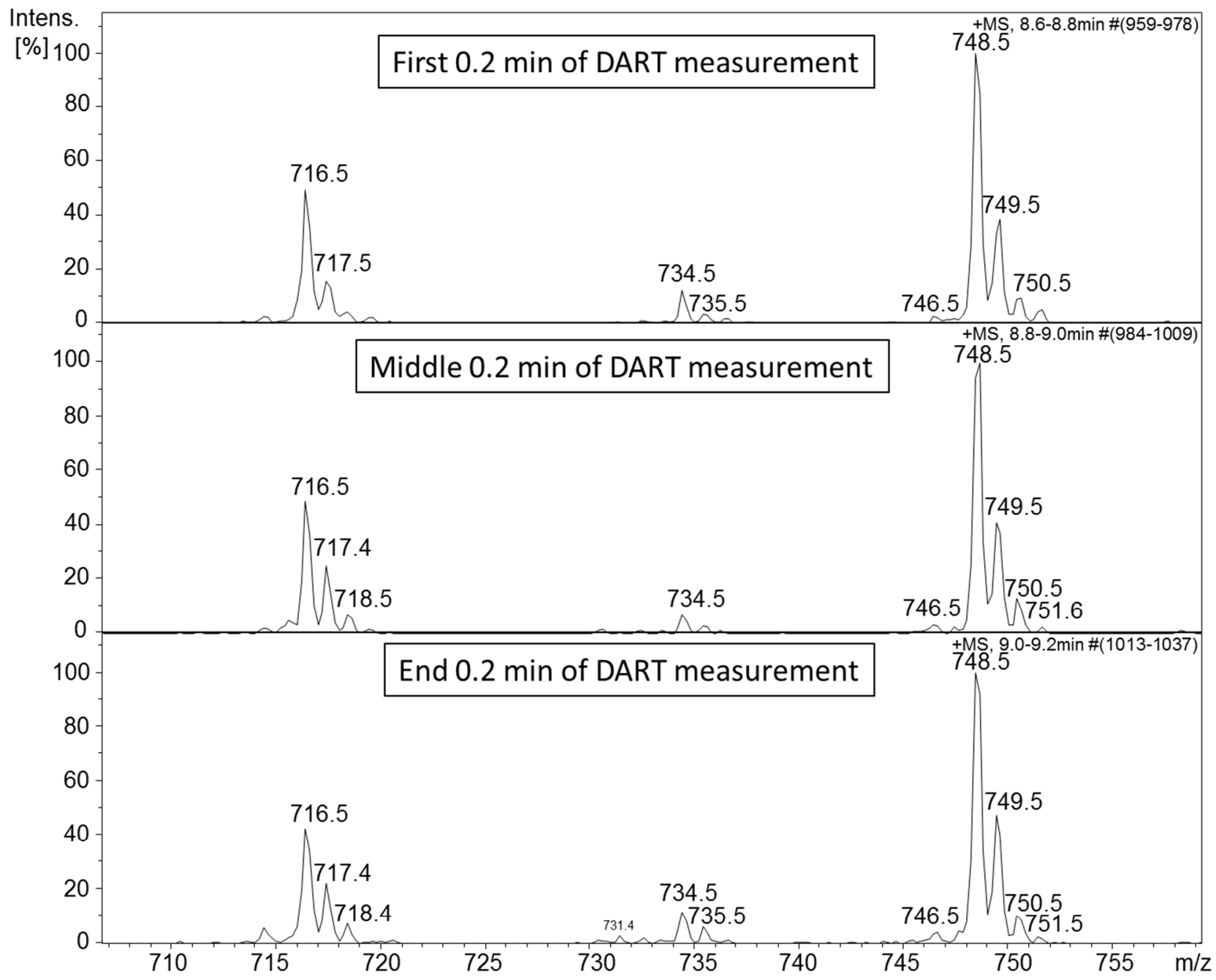

Figure S-3. Full scan MS after a $60 \mathrm{~s}$ erythromycin A in stillo reaction with $0.1 \%$ formic acid. Mass spectra originating from the first, middle and last $0.2 \mathrm{~min}$ of the DART-MS droplet measurement. 


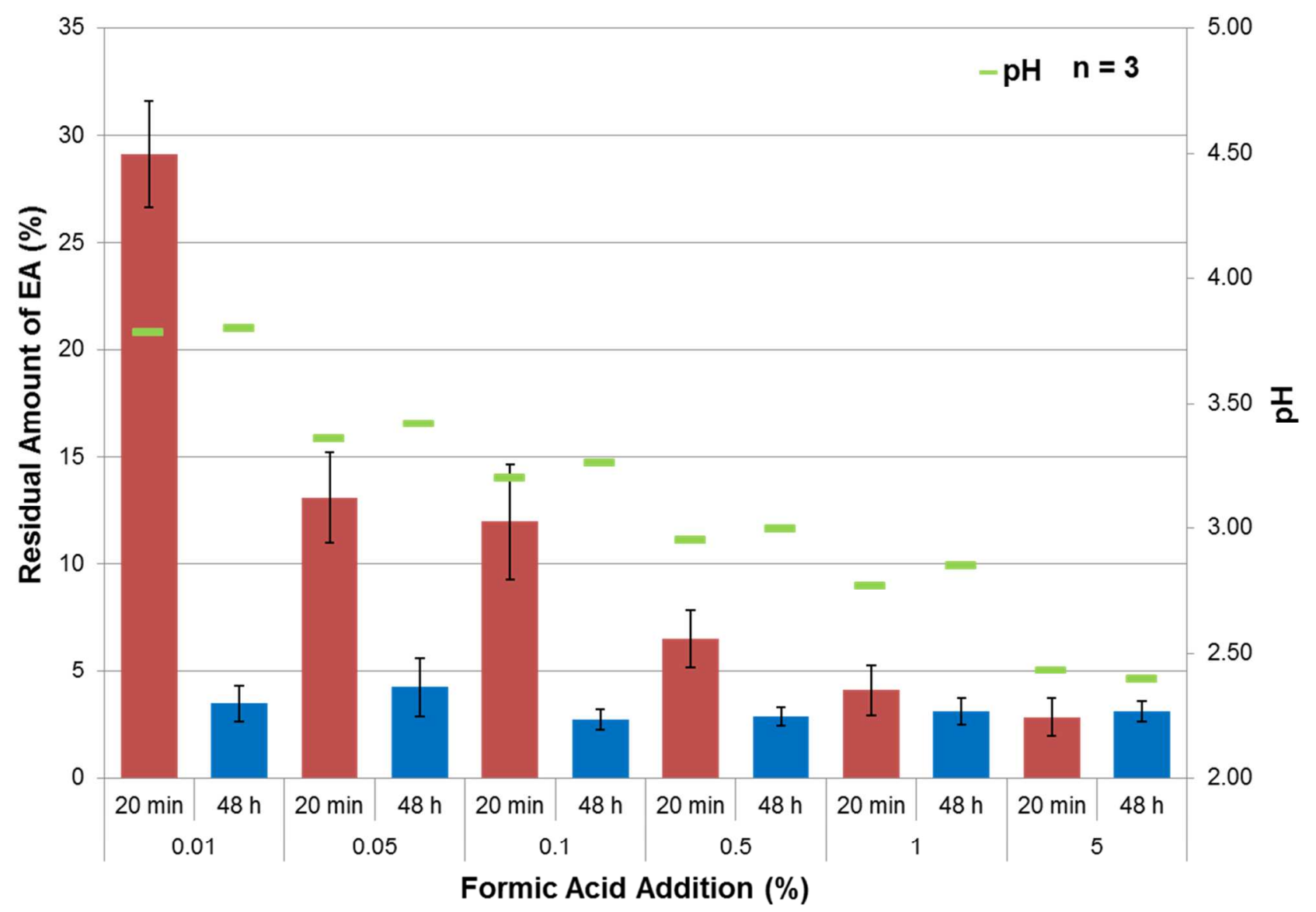

Figure S-4. Results of the erythromycin A degradation reaction for in vitro experiments. Faster EA degradation was marked by the increasing acid concentration and a relative decrease of ${ }^{\mathrm{m}, \mathrm{w}} \mathrm{pH}$. 


\section{Droplet Evaporation over Reaction Time}

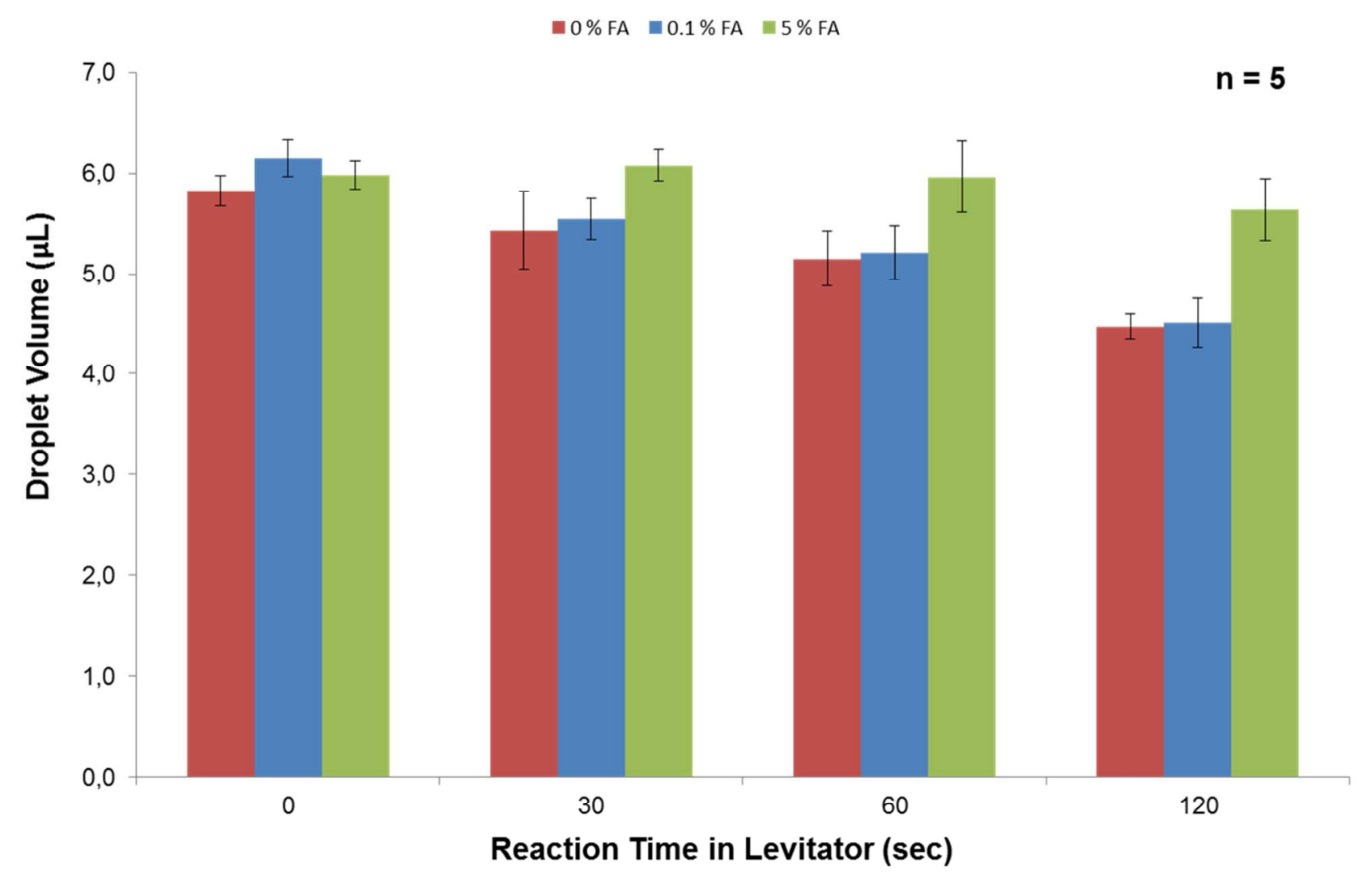

Figure S-5. Evaporation experiments monitoring the change of the measured droplet volume for the initial $6 \mu \mathrm{L}$ droplets and over the three set in stillo reaction times (30, 60, $120 \mathrm{~s})$. 


\section{Calculated pH Changes with Droplet Evaporation}

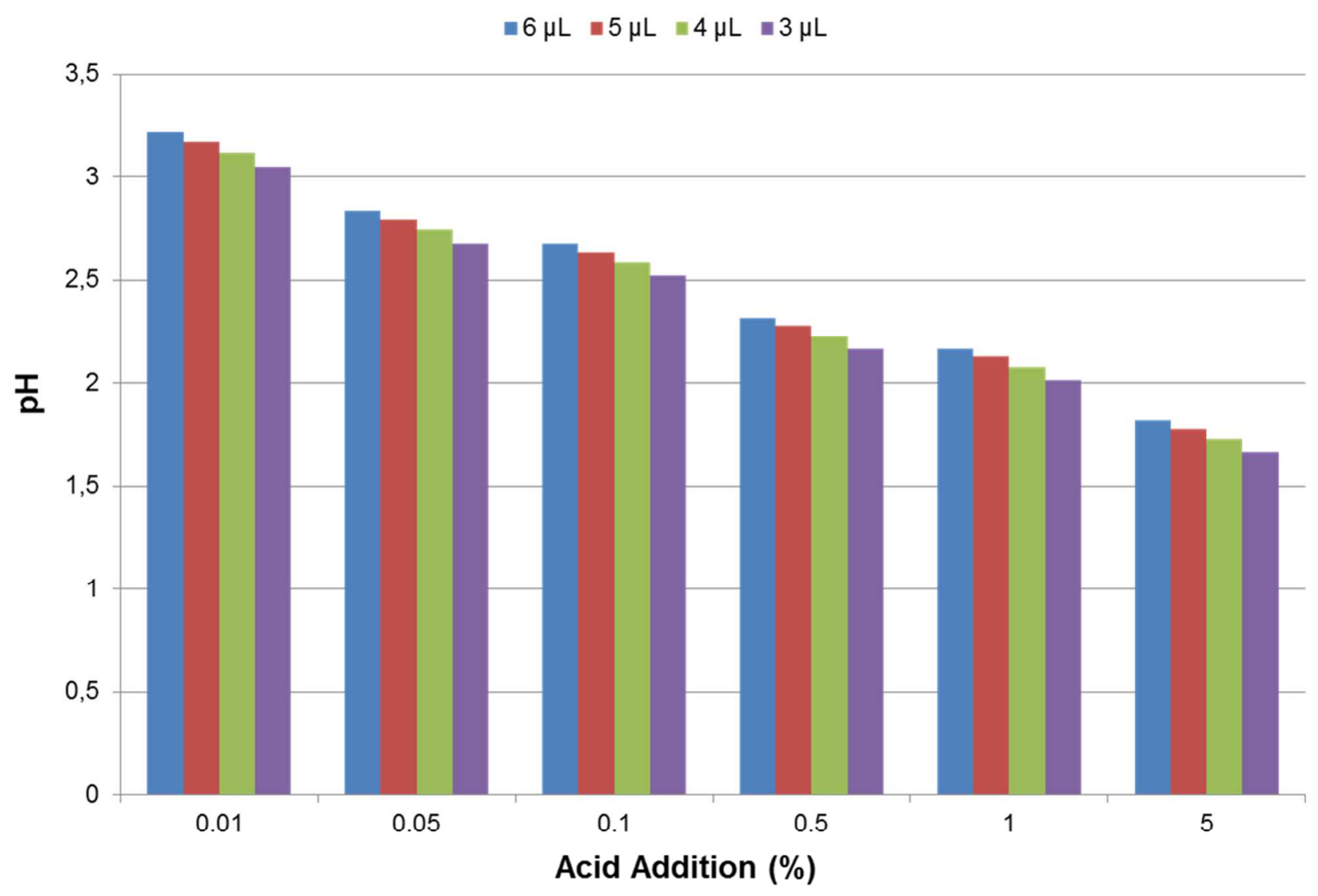

Figure S-6. Calculated changes of droplet $\mathrm{pH}$ for varying formic acid additions and droplet evaporation rates from the initial $6 \mu \mathrm{L}$ volume to a minimum volume of $3 \mu \mathrm{L}$. 